\title{
BMJ Open Influence of military component and deployment-related experiences on mental disorders among Canadian military personnel who deployed to Afghanistan: a cross-sectional survey
}

\author{
David Boulos, ${ }^{1}$ Deniz Fikretoglu ${ }^{2}$
}

To cite: Boulos D, Fikretoglu D. Influence of military component and deployment-related experiences on mental disorders among Canadian military personnel who deployed to Afghanistan: a crosssectional survey. BMJ Open 2018;8:e018735. doi:10.1136/ bmjopen-2017-018735

- Prepublication history and additional material for this paper are available online. To view these files, please visit the journal online (http://dx.doi. org/10.1136/bmjopen-2017018735).

Received 18 July 2017 Revised 18 December 2017 Accepted 12 January 2018

\section{Check for updates}

${ }^{1}$ Directorate of Mental Health, Canadian Forces Health Services Group, Ottawa, Ontario, Canada ${ }^{2}$ Defence Research and Development Canada, Toronto, Ontario, Canada

Correspondence to

David Boulos;

david.boulos@forces.gc.ca

\section{ABSTRACT}

Objective The primary objective was to explore differences in mental health problems (MHP) between serving Canadian Armed Forces (CAF) components (Regular Force (RegF); Reserve Force (ResF)) with an Afghanistan deployment and to assess the contribution of both component and deployment experiences to MHP using covariate-adjusted prevalence difference estimates. Additionally, mental health services use (MHSU) was descriptively assessed among those with a mental disorder

Design Data came from the 2013 CAF Mental Health Survey, a cross-sectional survey of serving personnel $(\mathrm{n}=72629)$. Analyses were limited to those with an Afghanistan deployment (population $n=35311$; sampled $\mathrm{n}=4854$ ). Logistic regression compared MHP between RegF and ResF members. Covariate-adjusted prevalence differences were computed.

Primary outcome measure The primary outcomes were MHP, past-year mental disorders, identified using the WHO's Composite International Diagnostic Interview, and past-year suicide ideation.

Results ResF personnel were less likely to be identified with a past-year anxiety disorder (adjusted OR $(A O R)=0.72(95 \% \mathrm{Cl} 0.58$ to 0.90$)$ ), specifically both generalised anxiety disorder and panic disorder, but more likely to be identified with a past-year alcohol abuse disorder (AOR=1.63 (95\% Cl 1.04 to 2.58)). The magnitude of the covariate-adjusted disorder prevalence differences for component was highest for the any anxiety disorder outcome, $2.8 \%$ (95\% Cl 1.0 to 4.6); lower for ResF. All but one deployment-related experience variable had some association with MHP. The 'ever felt responsible for the death of a Canadian or ally personnel' experience had the strongest association with MHP; its estimated covariate-adjusted disorder prevalence difference was highest for the any (of the six measured) mental disorder outcome (11.2\% (95\% Cl 6.6 to 15.9)). Additionally, ResF reported less past-year MHSU and more past-year civilian MHSU.

Conclusions Past-year MHP differences were identified between components. Our findings suggest that although deployment-related experiences were highly associated with MHP, these only partially accounted for MHP differences between components. Additional research is

\section{Strengths and limitations of this study}

- The survey sample was moderately large with a high response rate and thus allows for more detailed and representative analyses.

- The study is a cross-sectional survey and subject to the biases associated with this study design.

- The study was implemented among currently serving personnel and thus excludes those who had already released from service; an unknown fraction may have released because of mental health problems but such individuals are likely to be similarly distributed between both military components.

needed to further investigate MHSU differences between components.

\section{INTRODUCTION}

More than 40000 Canadian Armed Forces (CAF) personnel deployed in support of the mission in Afghanistan between 2001 and 2014. Findings from Canada and its allies ${ }^{1-7}$ have shown that a substantial minority of personnel with a past deployment to the conflicts in Southwest Asia have mental health problems (MHP), many apparently related to their deployment. The occurrence of MHP among personnel has important implications for military organisations; they are a leading cause of impaired productivity, ${ }^{8}$ absenteeism $^{8}$ and turnover, ${ }^{2}$ and mental healthcare represents a large and growing proportion of health services delivered by military organisations. ${ }^{10-12}$

Many factors influence the development of MHP among military populations. An elevated risk has been identified among personnel deployed to higher threat locations, ${ }^{3} 413$ Army personnel, ${ }^{13} 14$ lower rank personnel, ${ }^{13}$ 14 women, $^{15}$ Reservists, ${ }^{16}{ }^{17}$ 
personnel with past traumatic experiences, ${ }^{18}$ those with multiple deployments ${ }^{19}$ and those with more prolonged deployments. ${ }^{20}$ Additionally, combat exposure has been identified as a strong and independent predictor of postdeployment MHP. ${ }^{162122}$ Past research has demonstrated that a majority of those with combat-related deployments develop few or no $\mathrm{MHP}^{21}{ }^{23}$; however, serious MHPs do occur. Deployment experiences, whether related to life-threatening combat, moral injury ${ }^{24}$ or other traumatising exposures, have been shown to have a negative influence on mental health ${ }^{162122}$ and behaviours (eg, alcohol misuse $^{25}$ and risk taking ${ }^{26}$ ) among service members. In this light, the presence of impactful deployment experiences may mediate much of the elevated MHP risk that past research has attributed to lower rank, Army service, Reserve Force (ResF) and deployment location. ${ }^{27} 28$

The influence of deployment experiences on MHP has largely been unexplored in studies that were focused on comparing the mental health of Regular Force (RegF) and ResF personnel with prior difficult deployments. Studies from the USA ${ }^{161729}$ and $\mathrm{UK}^{27}$ suggest that ResF personnel returning from deployment tend to have a greater prevalence of MHP and while prior deployment experiences have been noted as one possible reason, further assessment is warranted. The present study addresses this limitation by comparing common MHP between RegF and ResF personnel in the CAF and investigates whether identified differences might be explained by differences in deployment experiences after systematically adjusting for differences in individual characteristics and baseline vulnerabilities (eg, proxies for lack of social support $^{2230}$ ), past non-military traumatic life experiences, predeployment and postdeployment training (eg, mental health training) and deployment characteristics.

The two components (ie, RegF and ResF) in the CAF differ subtly. RegF personnel commit to a period of fulltime military service, and during this period they are fully covered for no-cost mental health services from the CAF mental health system. In comparison, ResF personnel generally perform similar duties as their RegF counterpart but their employment can be either part-time or fulltime. During periods of active service, ResF personnel are eligible for CAF mental health services, especially if the illness or injury is determined to be related to military service. However, some ResF members may be less likely to access the no-cost military mental health services for reasons that may be related to real or perceived ineligibility for CAF services, preference or other reasons. Additionally, mental health services within the civilian system have some associated cost and ResF personnel who decide to access civilian mental health services may delay helpseeking due to cost considerations.

Notably, the CAF mental health system is arguably better resourced and optimised to aid military personnel with MHP when compared with the Canadian civilian system. ${ }^{31}$ ResF personnel who receive mental healthcare from the civilian system may thus be less than optimally serviced and, in practice, there is some evidence that
ResF personnel are encountering barriers that either limit their access to CAF mental healthcare or that lead them to choose not to use it. ${ }^{32}$ This suggests that ResF members may be using CAF mental health services less optimally relative to their $\mathrm{RegF}$ counterparts, which may be reflected in MHP prevalence differences. That is, differences in the amount, timing (delay) and quality of mental health services use (MHSU) care may manifest as symptoms being more persistent and, ultimately, more prevalent in one component relative to the other.

The primary objectives of this study were to explore differences in prevalent MHP between active service RegF and ResF CAF personnel with a past Afghanistan deployment, to assess the influence of deployment experiences on identified MHP differences between components and, specifically, to quantify an estimate of the contribution of both component and deployment experiences to prevalent MHP (ie, six measured past-year mental disorders and past-year suicide ideation) using covariate-adjusted prevalence difference estimates. Additionally, a secondary objective was to descriptively investigate component differences in their MHSU among those with one or more of the six identified mental disorders.

\section{METHODS}

\section{Study population and sampling}

Data came from a cross-sectional population-based survey of active service CAF personnel (2013 Canadian Forces Mental Health Survey), ${ }^{31}$ and were collected between April and August 2013 by Statistics Canada, Canada's national statistical agency. The sampling frame, created in September 2012, consisted of CAF personnel that administrative data indicated were in active service $(n=72629)$ and 35311 of these individuals had an Afghanistan-related deployment: 4857 ResF and 30454 RegF personnel. A stratified sampling approach was implemented with strata that were based on three military rank groupings (junior non-commissioned member (JNCM), senior non-commissioned member (SNCM) or officer) and component (ResF or RegF). Within strata the survey sample was selected using systematic sampling; individuals were sorted by service (Army, Navy, Air Force), support base, gender and first language. The resulting sample among those with an Afghanistan deployment contained 1469 (response rate: 79\%) ResF and 3385 (response rate: $80 \%)$ RegF participants. The strata and sorting variables were chosen to ensure sufficient numbers were sampled from subgroups in the study population that have low numbers and to permit their comparison (eg, rank can be a proxy for many factors, it has been shown to be associated with a number of outcomes and higher ranks have a lower representation in the study population). The original sample size for this survey was chosen by Statistics Canada such that a past-year post-traumatic stress disorder (PTSD) prevalence could be estimated with a margin of error of no more than $\pm 0.7 \%$. The analysis in this article was restricted to the participants with an 
Afghanistan deployment. All participants provided their informed consent before being interviewed. Sampling weights were provided by Statistics Canada and these permitted the generation of statistics that were representative of the population. Further details on this survey are available elsewhere. ${ }^{31}$

\section{Survey content}

Outcome variables: mental disorders and suicide ideation

The survey assessed past-year major depressive episode (MDE), PTSD, generalised anxiety disorder (GAD), panic disorder (PD), alcohol abuse and alcohol dependence using the WHO's Composite International Diagnostic Interview (CIDI), version 3.0 ${ }^{33}{ }^{34}$; the CIDI uses the Diagnostic and Statistical Manual of Mental Disorders (DSM) IV criteria for these disorders. Three additional aggregate outcomes were used: (1) alcohol use disorder (AUD), including alcohol abuse or dependence; (2) any anxiety disorder, including PTSD, GAD or PD; and (3) any of the six measured mental disorders. Past-year suicide ideation was determined based on whether respondents indicated having thought about committing suicide in the past 12 months.

\section{Military and sociodemographic information}

The primary covariate of interest was component and this information was confirmed during survey implementation. The following sociodemographic and military characteristics were also available from the survey data set: sex, age category $(17-24,25-34,35-44,45-60$ years), military rank (JNCM, SNCM and officer), service (Army, Navy or Air Forces), marital status, highest education level attained, racial background (white, non-white or multiple), household income and indication of having difficulty meeting basic expenses. Variable categorisations were based either on previous work with these data ${ }^{35}$ or its distribution.

\section{Lifetime potentially traumatic experiences}

The CIDI $^{33}{ }^{34}$ module on PTSD inquired about lifetime exposure to individual potentially traumatic experiences that included: combat experience, relief worker in a war zone, civilian in a war zone, civilian in region of terror, refugee, kidnapped, toxic chemical exposure, automobile accident, life-threatening accident, natural disaster, man-made disaster, life-threatening illness, beaten as a child by caregiver, beaten by spouse/romantic partner, beaten by other, mugged/threatened with a weapon, sexual assault, unwanted sexual touching, stalked, unexpected death of a loved one, child's serious illness, traumatic event to love one, witnessed intimate violence, witnessed death or dead body, accidentally caused serious injury, purposely injured/killed other, saw atrocities and 'other' (non-specific). The presence of each lifetime potentially traumatic experience (LTE) was individually assessed; however, the refugee LTE had very few affirmative responses $(<1 \%)$ and it was grouped with the 'other' traumatic experiences category.
Child abuse

Physical abuse, sexual abuse and exposure to intimate partner violence experienced before the age of 16 were assessed using items from the Childhood Experiences of Violence Questionnaire, a valid and reliable tool developed for assessing youth victimisation. ${ }^{36}$ Information was collected from all respondents aged 18 years or older and frequency thresholds were imposed, as per the questionnaire guidelines ${ }^{36}$ to identify the presence of these three types of child abuse experiences.

\section{Mental health training}

Participants were asked whether they received mental health or resilience training over the past 5 years in preparation for a CAF deployment and/or at the end of a CAF deployment. The CAF's resilience and mental health training programme was implemented in January 2008 with a focus on educating members on mental illness awareness and stigma reduction. In September 2009, this programme was further integrated across the deployment cycle and included instruction with an additional emphasis on prevention and psychological resilience. ${ }^{37}$ Additionally, in-depth postdeployment mental health screening was introduced in 2002 and became fully implemented within the CAF in August 2004. ${ }^{37}$

\section{Deployment-related characteristics and experiences Deployment-related characteristics}

Participants were asked whether they ever had a previous deployment outside of North America, other than Afghanistan-related ones. Additionally, participants indicated the total number of months they spent away from home over the past 3 years because of military duties, which included temporary duty assignments, deployments, training or exercises and any other reason as part of military duties. This time away variable was assessed using categories determined by the data's distribution: none, $\leq 6,7-12,13-24$ and 25-36 months.

Administrative data for participants' Afghanistan-related deployment history were available and linked deterministically with the sample file prior to survey implementation. The data were used to calculate the interval (days) from most recent deployment return to interview date, ( $<1460$ ( $<4$ years), $1460-1824$ (4 years), 1825-2189 (5 years), 2190-2554 (6 years) and $\geq 2555$ ( $\geq 7$ years) ), number of deployments $(1, \geq 2)$, deployment location (Kabul or elsewhere in Afghanistan, Kandahar province, multiple locations, other Afghanistan related) and duration of all Afghanistan-related deployments $(\leq 120$, 121-240, 241-360, $\geq 361$ days). All variable categorisations were determined based on the data's distribution.

\section{Deployment-related experiences}

Eight deployment-related experiences (DEX) were assessed: (1) 'ever known someone who was seriously injured or killed' (DEX-1); (2) 'ever found yourself in a threatening situation where you were unable to respond because of the rules of engagement' (DEX-2); (3) 'ever 
been injured' (DEX-3); (4) 'ever seen ill or injured women or children who you were unable to help' (DEX4); (5) 'ever received incoming artillery, rocket or mortar fire' (DEX-5); (6) 'ever felt responsible for the death of a Canadian or ally personnel' (DEX-6); (7) 'ever had a close call, for example shot or hit but protective gear saved you' (DEX-7); and (8) 'ever had difficulty distinguishing between combatants and non-combatants' (DEX-8). Affirmative responses indicate whether each item was ever experienced during a CAF deployment. These deployment experience items were adapted from the Combat Experiences Scale that was developed by the Walter Reed Army Institute for Research, following pilot testing for this survey and prior assessment among CAF personnel. $^{38}$

\section{Past-year MHSU}

Participants were asked about their past-year MHSU (civilian or CAF services) for MHP, phrased as '... problems with their emotions, mental health, or the use of alcohol or drugs.' This included whether they saw or spoke on the telephone with any of the following help venues about their MHP: (1) psychiatrist, (2) family doctor, (3) psychologist, (4) nurse, (5) social worker, (6) the Operational Stress Injury Social Support service, (7) religious/spiritual advisor, (8) family member, (9) friend, (10) coworker/boss, or (11) 'other'. Additionally, pastyear medication usage (yes or no) to assist with MHP was queried as was perceived level of help received for each of the 11 help venues (helped a lot, some, a little or none; the latter two response categories were grouped due to small numbers).

Past-year civilian MHSU was queried, assessing whether participants saw or talked on the telephone with a civilian health professional for their MHP; respondents were asked to exclude after-hours services, CAF-referred services and those covered by use of the CAF Health Care Identification card, a supplementary component of CAF coverage. Individuals responding affirmatively to civilian MHSU were queried on the following possible reasons: (1) not eligible for CAF health services, (2) waiting time too long for CAF care, (3) felt CAF care would be inadequate, (4) transportation problems, (5) language problems, (6) personal or family responsibilities, (7) concerned about confidentiality, (8) concerned about career, (9) did not want to take time off, and (10) other.

Participants were additionally queried on whether, over the past year, they were hospitalised overnight or longer for their MHP and, in contrast, whether they ever felt that they needed help with their MHP but did not receive it.

The analyses on these MHSU variables were limited to participants with any of the six CIDI-identified past-year mental disorders.

\section{Statistical analysis}

The data were analysed using Stata for Windows, release 13 (StataCorp; College Station, Texas). We applied the final survey sample weights provided by Statistics Canada to generate population representative descriptive and regression statistics and the Taylor Series Linearization method $^{39}$ was used to generate SE estimates. Listwise deletion was used for missing values, resulting in the exclusion of $0.1 \%-3.0 \%$ of respondents $(0.1 \%-2.9 \%$ for ResF; $0.1 \%-3.3 \%$ for RegF).

For the primary objective, Wald $\mathrm{X}^{2}$ tests were used to assess associations between component (RegF and ResF) and each variable. We additionally used a series of logistic regression models to assess the unadjusted and adjusted association of component with the presence of each measured MHP in a systematic manner; model 1 assessed the unadjusted association (expressed as an OR), model 2 assessed the association adjusted for military and sociodemographic variables, model 3 additionally adjusted for LTE and child abuse variables, implemented as propensity scores regressed on component (ie, ResF as outcome) and categorised into quartiles, model 4 additionally adjusted for predeployment and postdeployment mental health training, and model 5 additionally adjusted for deployment-related characteristics and experiences. Moreover, three of the LTEs (ie, combat experience, relief worker in a war zone and saw atrocities) were determined via exploratory factor analysis to be highly associated with a deployment experience factor ${ }^{40}$; these were excluded from the model 3 assessment and assessed along with the other DEX variables in model 5 .

Two-way multiplicative and additive interactions were assessed between component and each of the eight DEXs as well as the three deployment-related LTEs. The relative excess risk due to interaction (RERI) assessed for the presence of an additive interaction. ${ }^{41}$

Reporting unadjusted prevalence estimates for the MHP outcomes by component are not optimal indicators as they reflect differences associated with each component and differences that are attributable to differing covariate profiles between components. Marginal standardisation approaches can produce estimates that are adjusted for the effect of differing covariate profiles on an outcome of interest, and thus produce clearer effect estimates. We used a marginal standardisation approach to estimate the study population proportion that, based on the final logistic regression model, would be expected to have each MHP outcome had they had the exposure or characteristic of interest; this approach operates by statistically forcing the total population to have the exposure or characteristic of interest (eg, ResF or RegF) while other covariates retain their observed value. ${ }^{42}$ Expected marginal prevalence differences (MPD) were computed for component (ResF vs RegF) and, additionally, for the DEX (presence vs absence) variables; a z-test assessed the MPD statistical significance with SEs computed using the delta method. ${ }^{42}$ These MPDs provide estimates of the increase or decrease in prevalence associated with the variable of interest and assume that confounding has largely been adjusted for in the model. 
For the secondary objective, Wald $\mathrm{X}^{2}$ tests were used to assess associations between component (RegF and ResF) and each MHSU variable.

\section{RESULTS}

\section{Survey population characteristics}

General

Sociodemographic and other military-associated characteristics are shown in table 1 for each component. With the exception of predeployment mental health training, each variable's distribution differed significantly by component.

Prevalence of a mental disorder, which included any of the six CIDI-measured disorders, was similar between RegF and ResF, $18.9 \%$ and $19.3 \%$, respectively (table 1 ). However, the prevalence of three specific disorders (any GAD, any alcohol abuse and any alcohol dependence), suicide ideation and the distribution of comorbid mental disorders did differ with statistical significance by component (table 1).

Additionally, many of the individual LTE and child abuse types differed significantly by component (online supplementary table 1).

\section{Deployment-related characteristics and experiences}

As indicated in table 2 and as expected, all measured deployment-related characteristics differed significantly by component. While all participants had an Afghanistan-related deployment, $56.6 \%$ of RegF and $39.9 \%$ of ResF additionally had a non-Afghanistan-related deployment. Mean time away over the past 3 years was 11.0 months (95\% CI 10.7 to 11.3 ) and 8.7 months (95\% CI 8.4 to 9.0$)$ and mean time from last Afghanistan-related deployment to survey interview was 5.4 years (95\% CI 5.3 to 5.5 ) and 5.2 years (95\% CI 5.1 to 5.3 ) for $\operatorname{RegF}$ and ResF, respectively. A majority of individuals had a single Afghanistan-related deployment, the deployment location was predominantly Kandahar province, and the cumulative duration of Afghanistan deployments was predominantly 8 months or less.

Among the eight specifically assessed deployment experiences, all except 'ever been injured' and 'ever felt responsible for the death of a Canadian or ally personnel' were significantly more common among ResF (table 2). Additionally, among the three LTEs that were deployment related, only 'combat experience' was more common among ResF.

\section{Logistic regression results}

Table 3 presents the results of the logistic regression analyses that assess the association of component (ResF vs $\mathrm{RegF}$ ) with the individual and grouped MHP after subsequently adjusting for additional covariate groups (model 1 to model 5 ). In the fully adjusted models (model 5 ), the odds of a past-year anxiety disorder (adjusted OR (AOR): $0.72 ; 95 \%$ CI 0.58 to 0.90 ), GAD (AOR: $0.69 ; 95 \%$ CI 0.51 to 0.93 ) and PD (AOR: $0.70 ; 95 \%$ CI 0.51 to 0.96 ) were significantly less likely among ResF while the odds of a past-year alcohol abuse disorder (AOR: 1.63; 95\% CI 1.03 to 2.58 ) was significantly more likely among ResF. Online supplementary table 2 presents the AOR results for all model 5 covariates.

The association of the measured deployment-related characteristics had mixed but mostly non-significant associations with MHP (table 3). Other non-Afghanistan deployments tended to be protective for an MHP, especially anxiety disorders and MDE. Shorter intervals from Afghanistan deployment return to survey interview tended to be associated with higher odds of suicide ideation, MDE, GAD, PTSD and PD. The odds of PD was significantly lower among those with a Kandahar province deployment location. There was a tendency for individuals with the highest cumulative duration of Afghanistan-related deployments (ie, $\geq 361$ days) to have a lower odds of an MHP, especially suicide ideation and MDE.

\section{Deployment-related experiences}

The measured DEX had a number of significant associations with MHP (table 3). With the exception of DEX-5 (ie, ever received incoming artillery, rocket or mortar fire) each DEX was significantly associated with at least one of the measured MHPs. None of the measured DEXs had an association with alcohol abuse disorder and only DEX-3 (ie, ever been injured) was associated with a higher odds of alcohol dependence disorder (AOR: 1.69; 95\% CI 1.02 to 2.78). DEX-6 (ie, ever felt responsible for the death of a Canadian or ally personnel) had the strongest association with MHP; however, the AOR for alcohol abuse and alcohol dependence only reached statistical significance as the combined AUD.

Among the deployment-related LTEs (table 3), combat experience was associated with a lower odds of MDE but a higher odds of PTSD and PD; relief worker in a war zone was associated with a higher odds of any mental disorder, any anxiety disorder, PTSD and alcohol dependence; and saw atrocities was only associated with a higher odds of PD.

\section{Interactions}

Component by DEX interactions were largely non-significant on the measured MHP. However, multiplicative interactions were identified for component by DEX-8 on MDE and on alcohol abuse disorder outcomes; the odds of MDE was higher and significant with this DEX but only among RegF (AOR (DEX-8)=1.74, 95\% CI 1.33 to 2.28) and the odds of an alcohol abuse disorder was elevated for ResF relative to RegF but only among those without this DEX (among no DEX-8, AOR (ResF vs RegF) $=4.92,95 \%$ CI 1.51 to 16.01 ). While significant multiplicative interactions were also noted for component by the combat experience LTE on the alcohol dependence disorder outcome and component by the relief worker in a war zone LTE on suicide ideation, the individual AOR making up these interactions was non-significant; however, there was a tendency for the LTE exposure to be associated with an 
Table 1 Mental health problems, military and sociodemographic characteristics

Characteristic

\section{Past-year mental health problems}

Comorbid disorders*

\begin{tabular}{|c|c|c|c|c|}
\hline MDE only & 3.8 & 3.2 to 4.5 & 3.7 & 2.9 to 4.4 \\
\hline PTSD only & 2.4 & 1.9 to 2.9 & 1.8 & 1.3 to 2.4 \\
\hline PD only & 1.5 & 1.1 to 1.9 & 1.4 & 0.94 to 1.8 \\
\hline Alcohol abuse only & 1.1 & 0.80 to 1.5 & 2.8 & 2.1 to 3.4 \\
\hline Alcohol dependence only & 0.6 & 0.38 to 0.90 & 1.4 & 0.95 to 1.8 \\
\hline PTSD, MDE, other & 2.4 & 1.9 to 2.9 & 1.8 & 1.3 to 2.4 \\
\hline Mixed-no PTSD & 2.5 & 2.0 to 3.0 & 2.3 & 1.7 to 2.9 \\
\hline None identified & 81.2 & 79.9 to 82.5 & 81.1 & 79.6 to 82.7 \\
\hline \multicolumn{5}{|l|}{ Individual mental health problems } \\
\hline Any PTSD & 7.7 & 6.9 to 8.6 & 6.8 & 5.8 to 7.8 \\
\hline Any PD§ & 5.1 & 4.3 to 5.8 & 4.1 & 3.3 to 4.9 \\
\hline Any GAD* & 5.8 & 5.0 to 6.5 & 4.1 & 3.3 to 4.8 \\
\hline Any alcohol abuse disorder* & 1.9 & 1.5 to 2.4 & 3.6 & 2.8 to 4.3 \\
\hline Any alcohol dependence* & 1.4 & 1.1 to 1.8 & 2.2 & 1.6 to 2.8 \\
\hline Any AUD* & 3.4 & 2.8 to 4.0 & 6.3 & 5.3 to 7.2 \\
\hline Any suicide ideation* & 4.6 & 3.9 to 5.3 & 5.8 & 4.9 to 6.8 \\
\hline \multicolumn{5}{|c|}{ Military and sociodemographic characteristics } \\
\hline \multicolumn{5}{|l|}{ Sex ${ }^{*}$} \\
\hline $45-60$ & 24.4 & 23.2 to 25.7 & 28.6 & 27.1 to 30.1 \\
\hline \multicolumn{5}{|l|}{ Rank* $^{*}$} \\
\hline JNCM & 48.2 & 47.9 to 48.5 & 48.2 & 48.0 to 48.5 \\
\hline SNCM & 32.2 & 31.9 to 32.4 & 29.0 & 28.8 to 29.2 \\
\hline Officer & 19.6 & 19.4 to 19.8 & 22.8 & 22.6 to 23.0 \\
\hline \multicolumn{5}{|l|}{ Service* } \\
\hline Navy & 13.8 & 12.7 to 14.8 & 3.6 & 2.9 to 4.3 \\
\hline Army & 64.6 & 63.1 to 66.1 & 85.2 & 83.9 to 86.5 \\
\hline Air Force & 21.7 & 20.4 to 23.0 & 11.2 & 10.0 to 12.4 \\
\hline \multicolumn{5}{|l|}{ Marital status* } \\
\hline Married/common & 74.7 & 73.3 to 76.1 & 59.8 & 58.0 to 61.6 \\
\hline Single & 16.5 & 15.3 to 17.7 & 33.9 & 32.2 to 35.7 \\
\hline
\end{tabular}

Continued
Regular Force personnel

Sample $n=3385$

Weighted $\mathrm{N}=29060$

\section{Reserve Force personnel}

Sample $n=1469$

Weighted $\mathrm{N}=4480$

$\% \quad 95 \% \mathrm{Cl}$

$\%$ $95 \% \mathrm{Cl}$ 


\begin{tabular}{|c|c|c|c|c|}
\hline \multirow{2}{*}{ Characteristic } & \multicolumn{2}{|c|}{ Regular Force personnel } & \multicolumn{2}{|c|}{ Reserve Force personnel } \\
\hline & \multicolumn{2}{|c|}{$\begin{array}{l}\text { Sample } n=3385 \\
\text { Weighted } N=29060\end{array}$} & \multicolumn{2}{|c|}{$\begin{array}{l}\text { Sample } n=1469 \\
\text { Weighted } N=4480\end{array}$} \\
\hline Widowed, separated or divorced & 8.7 & 7.9 to 9.6 & 6.3 & 5.3 to 7.2 \\
\hline \multicolumn{5}{|l|}{ Education* } \\
\hline Some postsecondary & 9.2 & 8.2 to 10.1 & 9.4 & 8.3 to 10.5 \\
\hline Postsecondary graduate & 55.7 & 54.2 to 57.2 & 68.2 & 66.4 to 69.9 \\
\hline \multicolumn{5}{|l|}{ Racial background* } \\
\hline White & 93.1 & 92.3 to 93.9 & 89.7 & 88.5 to 90.9 \\
\hline$<50000$ & 1.2 & 0.88 to 1.6 & 11.6 & 10.3 to 12.9 \\
\hline $50000-69000$ & 14.8 & 13.7 to 15.9 & 12.9 & 11.6 to 14.3 \\
\hline $70000-89000$ & 21.9 & 20.6 to 23.2 & 17.0 & 15.5 to 18.4 \\
\hline$\geq 90000$ & 62.1 & 60.6 to 63.5 & 58.5 & 56.7 to 60.3 \\
\hline \multicolumn{5}{|l|}{ Income difficulty§ } \\
\hline Yes & 6.1 & 5.4 to 6.9 & 7.2 & 6.2 to 8.2 \\
\hline No & 93.9 & 93.1 to 94.6 & 92.8 & 91.8 to 93.8 \\
\hline \multicolumn{5}{|c|}{ Mental health training (in past 5 years) } \\
\hline Predeployment & 58.8 & 57.3 to 60.4 & 59.6 & 57.8 to 61.5 \\
\hline
\end{tabular}

${ }^{*}$ Regular Force and Reserve Force differ significantly (Wald $\mathrm{X}^{2} \mathrm{P} \leq 0.05$ ).

†Any of the following: major depressive episode, generalised anxiety disorder, panic disorder, post-traumatic stress disorder, alcohol abuse disorder or alcohol dependence disorder.

$\ddagger$ Any of the following: generalised anxiety disorder, panic disorder or post-traumatic stress disorder.

$\S$ Regular Force and Reserve Force differ with marginal significance (Wald $\mathrm{X}^{2} 0.05<\mathrm{P} \leq 0.10$ ).

AUD, alcohol use disorder (either alcohol abuse disorder or alcohol dependence disorder); GAD, generalised anxiety disorder; JNCM, junior non-commissioned member; MDE, major depressive episode; PD, panic disorder; PTSD, post-traumatic stress disorder; SNCM, senior noncommissioned member.

elevated AOR among RegF and for the ResF (vs RegF) AOR to be elevated in the absence of this LTE exposure.

Additive interactions were identified for component by DEX-8 on MDE (RERI $=-0.75,95 \%$ CI -1.29 to -0.21 ), where the marginal prevalence increased $4.4 \%$ (95\% CI 2.2 to 6.6 ) among RegF members with DEX-8 exposure (vs none) and did not change significantly among ResF; there was also a component by DEX-6 additive interaction on PTSD (RERI $=-1.80,95 \%$ CI -3.33 to -0.27 ), where the marginal prevalence increased 9.9\% (95\% CI 6.0 to 13.8) with DEX-6 exposure (vs none) among RegF and only $5.3 \%$ among ResF (95\% CI 1.1 to 9.4).

These significant multiplicative and additive interaction patterns are both similarly suggesting that the prevalence of some outcomes among ResF without these DEX or LTE are elevated relative to RegF and that the resulting changes occurring among individuals with these DEX or LTE exposures are generally not large enough to become significant for ResF but tends to be for RegF.
Marginal prevalence estimates

Marginal prevalence estimates for the influence of component and the DEX variables on MHP are presented in table 4. As explained in the Methods section, these are confounder-adjusted measures of effect. The largest MPDs were associated with DEX-6 (ie, ever felt responsible for the death of a Canadian or ally personnel). For component, the estimated MPD was highest for the any anxiety disorder outcome, $2.8 \%$ less for ResF.

\section{Past-year MHSU}

MHSU was assessed only among survey participants with any of the six CIDI-identified past-year mental disorders (table 5). Consultations with a psychiatrist, family doctor, psychologist, nurse, social worker and family member were all lower among the ResF component by $8 \%$ or more. Additionally, 33.3\% (95\% CI 29.0 to 37.6) of ResF individuals reported no MHSU consultations compared with $21.4 \%$ (95\% CI 18.4 to 24.5 ) among RegF. And similarly, 
Table 2 Deployment-related characteristics and experiences

\begin{tabular}{|c|c|c|c|c|}
\hline \multirow[b]{3}{*}{ Characteristic } & \multirow{2}{*}{\multicolumn{2}{|c|}{$\begin{array}{l}\text { Regular Force personnel } \\
\text { Sample } n=3385 \\
\text { Weighted } N=29060\end{array}$}} & \multirow{2}{*}{\multicolumn{2}{|c|}{$\begin{array}{l}\text { Reserve Force personnel } \\
\text { Sample } n=1469 \\
\text { Weighted } N=4480\end{array}$}} \\
\hline & & & & \\
\hline & $\%$ & $95 \% \mathrm{Cl}$ & $\%$ & $95 \% \mathrm{Cl}$ \\
\hline \multicolumn{5}{|l|}{ Deployment-related characteristics } \\
\hline \multicolumn{5}{|l|}{ Other deployments* } \\
\hline Non-Afghanistan deployment & 56.6 & 55.1 to 58.1 & 39.9 & 38.2 to 41.7 \\
\hline$\leq 6$ & 27.8 & 29.9 to 32.8 & 35.9 & 29.9 to 32.8 \\
\hline $7-12$ & 25.4 & 8.7 to 10.6 & 23.2 & 8.7 to 10.6 \\
\hline $13-24$ & 32.5 & 15.5 to 17.8 & 21.8 & 15.5 to 17.8 \\
\hline $25-36$ & 6.3 & 19.0 to 21.5 & 5.5 & 19.0 to 21.5 \\
\hline None & 8.0 & 20.8 to 23.4 & 13.6 & 20.8 to 23.4 \\
\hline $1825-2189$ days (5years) & 20.2 & 19.0 to 21.5 & 21.4 & 19.9 to 23.0 \\
\hline 2190-2554 days (6years) & 9.6 & 8.7 to 10.6 & 7.6 & 6.6 to 8.6 \\
\hline$\geq 2555$ days ( $\geq 7$ years) & 22.1 & 20.8 to 23.4 & 20.5 & 19.0 to 22.0 \\
\hline \multicolumn{5}{|l|}{ Total number of Afghanistan deployments* } \\
\hline 1 & 70.3 & 68.9 to 71.8 & 83.4 & 82.0 to 84.8 \\
\hline$\geq 2$ & 29.7 & 28.2 to 31.1 & 16.6 & 15.2 to 18.0 \\
\hline \multicolumn{5}{|l|}{ Afghanistan deployment location* } \\
\hline Kabul & 10.9 & 9.9 to 11.9 & 14.3 & 13.0 to 15.6 \\
\hline Kandahar & 53.5 & 51.9 to 55.0 & 68.3 & 66.6 to 70.0 \\
\hline \multicolumn{5}{|l|}{ Duration of Afghanistan deployments* (days) } \\
\hline$\geq 361$ & 15.8 & 14.6 to 16.9 & 9.4 & 8.3 to 10.5 \\
\hline \multicolumn{5}{|l|}{ Deployment-related experiences } \\
\hline Known someone seriously injured or killed (DEX-1)* & 70.0 & 68.5 to 71.4 & 74.0 & 72.3 to 75.7 \\
\hline $\begin{array}{l}\text { Ever found yourself in a threatening situation where you were unable to } \\
\text { respond because of rules of engagement (DEX-2)* }\end{array}$ & 30.9 & 29.4 to 32.3 & 33.6 & 31.8 to 35.4 \\
\hline Ever been injured (DEX-3) & 25.5 & 24.1 to 26.9 & 24.7 & 23.0 to 26.3 \\
\hline $\begin{array}{l}\text { Ever seen ill or injured women or children who you were unable to help (DEX- } \\
4)^{*}\end{array}$ & 42.0 & 40.4 to 43.5 & 47.1 & 45.2 to 49.0 \\
\hline Ever received incoming artillery, rocket or mortar fire $(\mathrm{DEX}-5)^{\star}$ & 69.4 & 68.0 to 70.9 & 77.6 & 76.0 to 79.2 \\
\hline Ever felt responsible for the death of Canadian or ally personnel (DEX-6) & 7.3 & 6.5 to 8.1 & 8.1 & 7.1 to 9.1 \\
\hline Ever had a close call (DEX-7) $)^{\star}$ & 25.4 & 24.0 to 26.8 & 30.0 & 28.3 to 31.8 \\
\hline $\begin{array}{l}\text { Ever had difficulty distinguishing between combatants and non-combatants } \\
(\text { DEX-8)* }\end{array}$ & 37.3 & 35.8 to 38.8 & 45.3 & 43.4 to 47.2 \\
\hline \multicolumn{5}{|l|}{ LTEs that were deployment related } \\
\hline Combat experience ${ }^{*}$ & 65.3 & 63.7 to 66.8 & 71.3 & 69.3 to 73.3 \\
\hline Relief worker in a war zone & 57.4 & 55.8 to 59.0 & 57.8 & 55.7 to 60.0 \\
\hline Saw atrocities & 24.4 & 23.0 to 25.8 & 25.1 & 23.3 to 27.0 \\
\hline
\end{tabular}

${ }^{*}$ Regular Force and Reserve Force differ significantly (Wald $\left.X^{2} \mathrm{P} \leq 0.05\right)$.

DEX, deployment-related experience; LTE, lifetime potentially traumatic experience. 


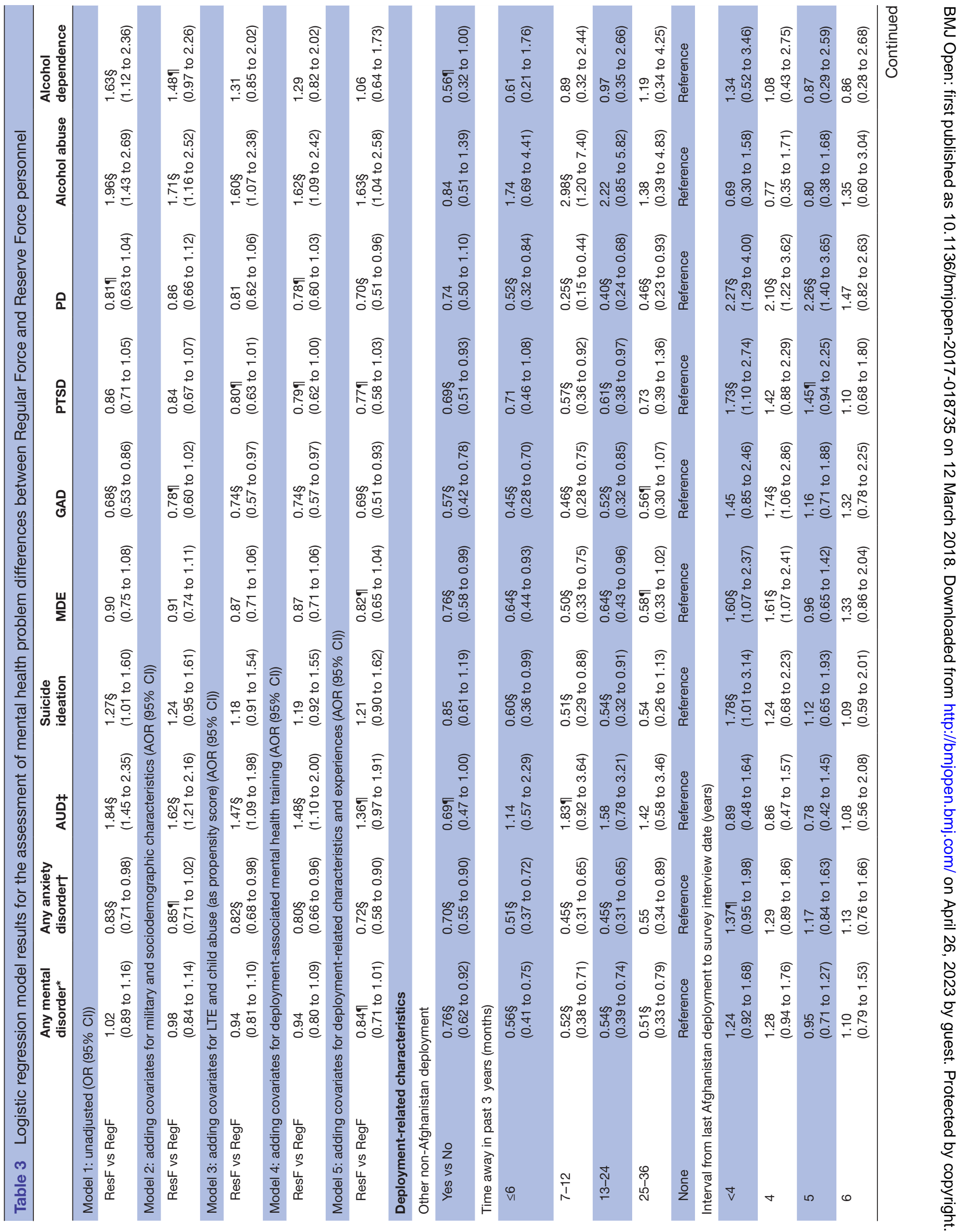




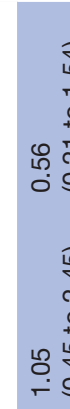

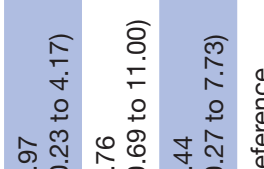

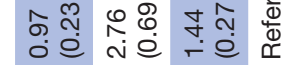

ब

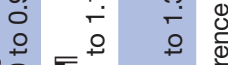

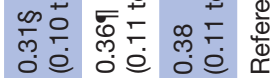

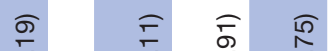

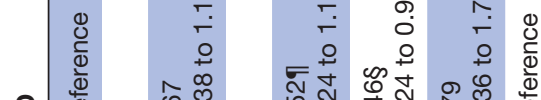

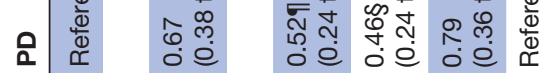

ळ

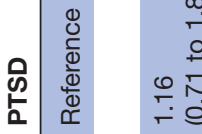

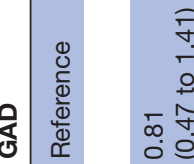

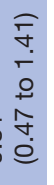

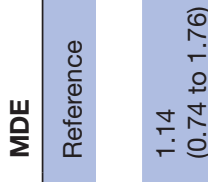

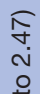

$\frac{0}{0}$

ஸे

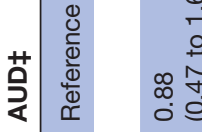

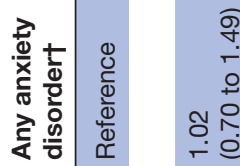

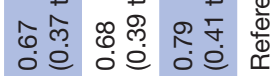

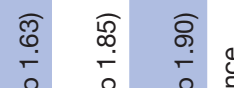

रִ

लె口 ळ

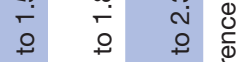

๙ู

ó

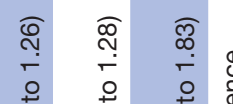

ธุ

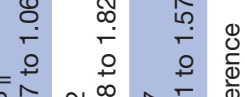

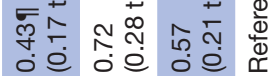

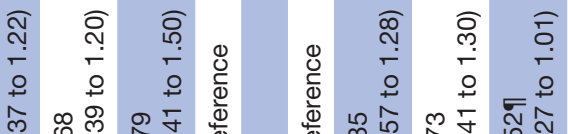

भุ

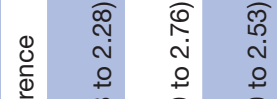

离

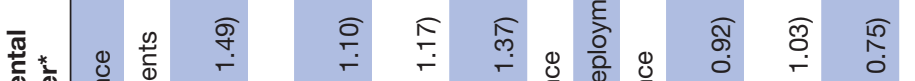

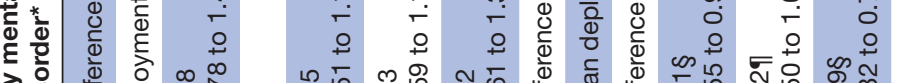

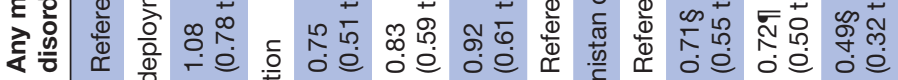

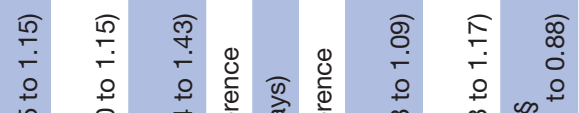

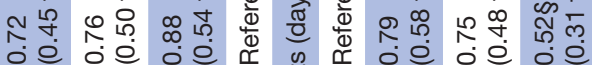

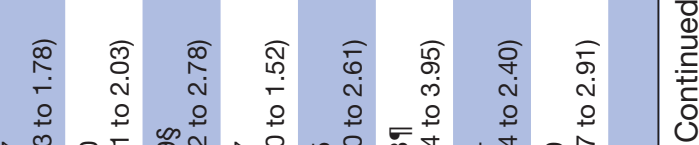

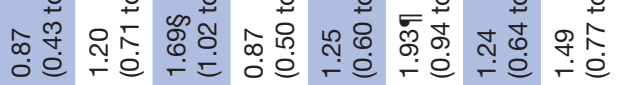

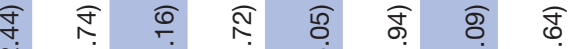

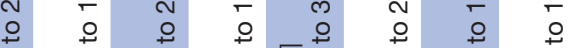

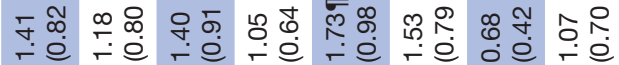

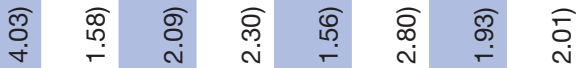

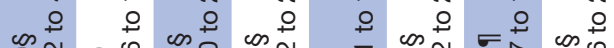

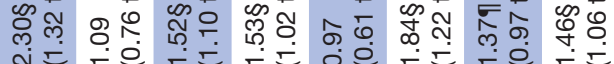

ণิ

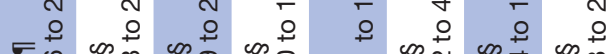

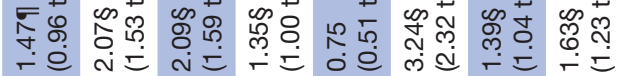

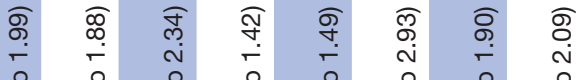
웅 cos 웅 ஸุ

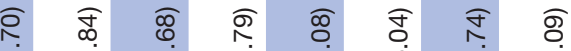

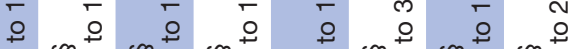

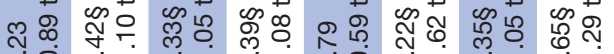

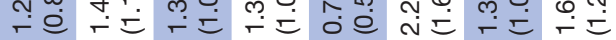

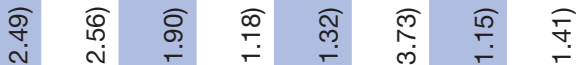
क

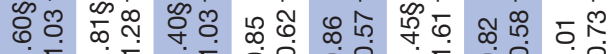
-

बू

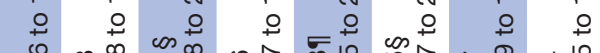

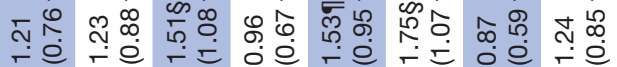

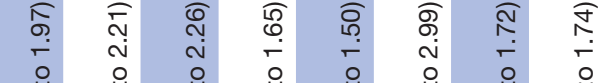
舟苞

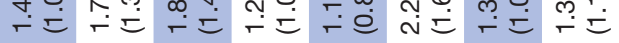

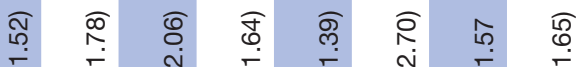

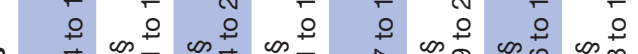
\& 
past-year medication use for MHPs was significantly lower among ResF (33.3\%; 95\% CI 29.0 to 37.6) compared with RegF (49.1\%; 95\% CI 45.3-52.8). These results correspond with the proportions indicating they needed help for MHPs but did not receive it, $39.0 \%$ (95\% CI 34.6 to 43.5) among ResF versus $31.2 \%$ (95\% CI 27.7 to 34.7 ) among RegF. Other than family member as an MHSU source, there were no statistically significant differences between components with respect to their perceived level of help received from the different MHSU sources.

As expected, ResF reported more past-year civilian MHSU (table 5) and, with the exception of other reasons, not being eligible for CAF health services was the most commonly reported justification (28.6\%; $95 \%$ CI 18.2 to 38.9).

\section{DISCUSSION \\ Key findings}

Among CAF personnel with an Afghanistan-related deployment, we found differences in MHP between components. However, after adjusting for potential confounders, ResF personnel only remained less likely to have a past-year anxiety disorder, both GAD and PD individually, and more likely to be identified with only a pastyear alcohol abuse disorder. Estimated covariate-adjusted prevalence differences for component were as high as $2.8 \%$.

There were some differences in DEXs between components that may be associated with a noted increase in ResF personnel being deployed during a harsher period of the Afghanistan mission or possibly other reasons such as predeployment training differences that may have influenced experience perceptions. We found that, with the exception of the 'ever received incoming artillery, rocket, or mortar fire' experience (DEX-5), each identified DEX had some association with at least one of the measured MHPs. The 'ever felt responsible for the death of a Canadian or ally personnel' experience (DEX6), a moral injury proxy, had the strongest association with MHP. None of the DEXs were associated with an alcohol abuse disorder and only the 'ever been injured' experience (DEX-3) had an association with an alcohol dependence disorder. The deployment-related LTEs were associated with MHP; combat experience was associated with a lower odds of MDE but a higher odds of PTSD and PD; being a relief worker in a war zone was associated with a higher odds of any mental disorder, any anxiety disorder, PTSD and alcohol dependence; and seeing atrocities was only associated with a higher odds of PD.

Among individuals with any of the identified past-year mental disorders, consultations with a psychiatrist, family doctor, psychologist, nurse, social worker and family member were all lower among the ResF by $8 \%$ or greater. More ResF personnel (33\%) reported no MHSU consultations compared with RegF (21\%). Past-year medication use for MHPs was lower among ResF and the proportion indicating they needed help for MHP but did not receive 


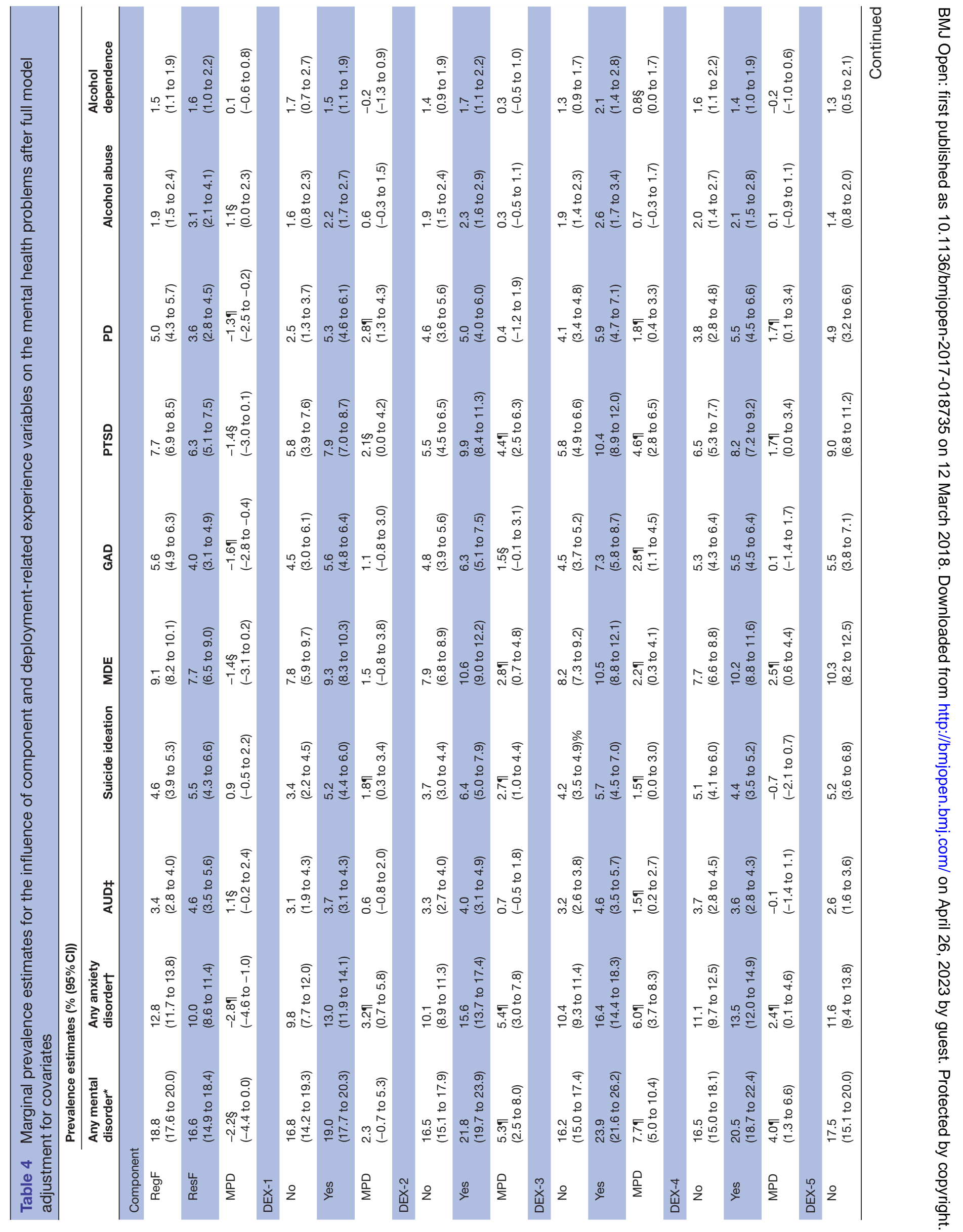




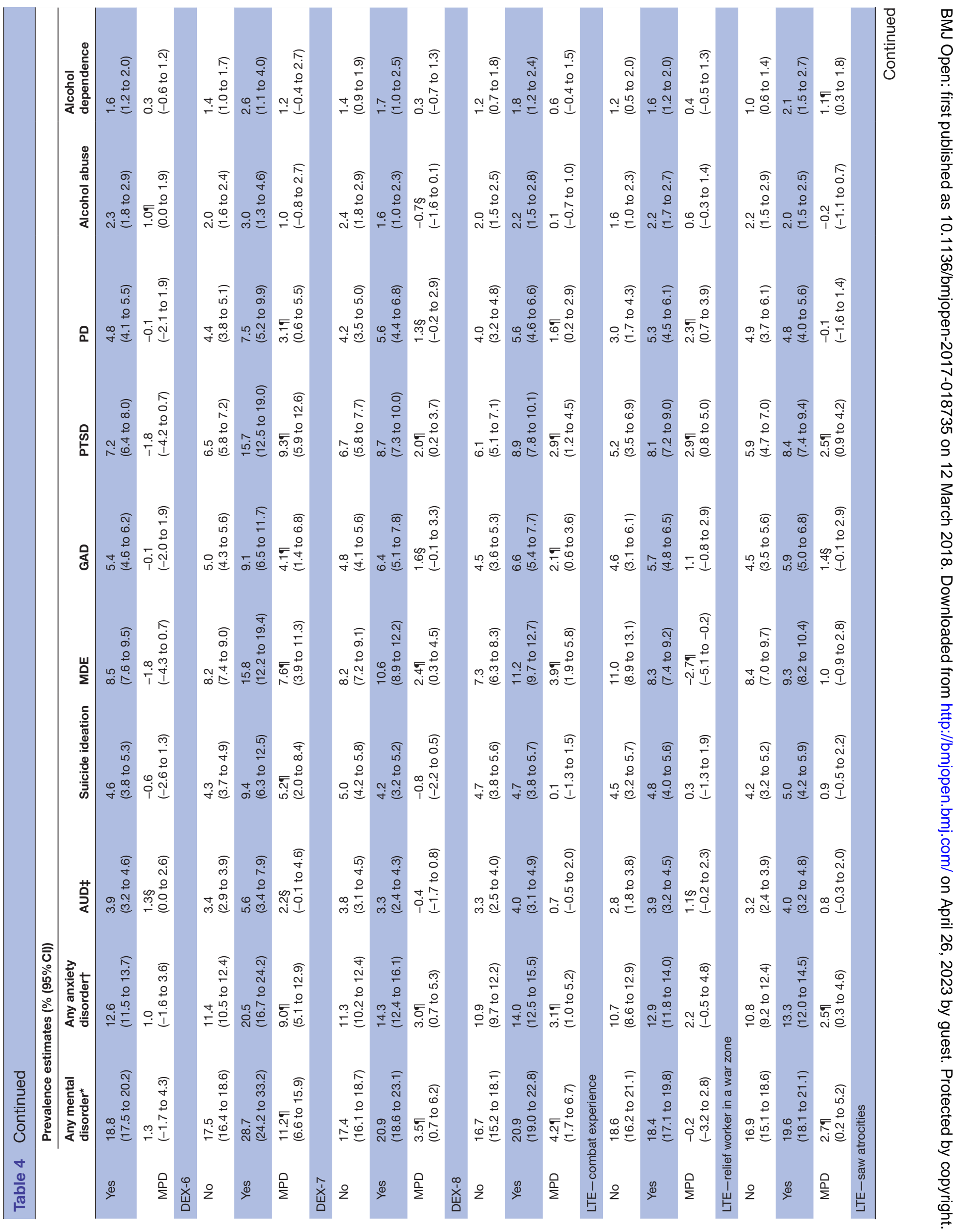




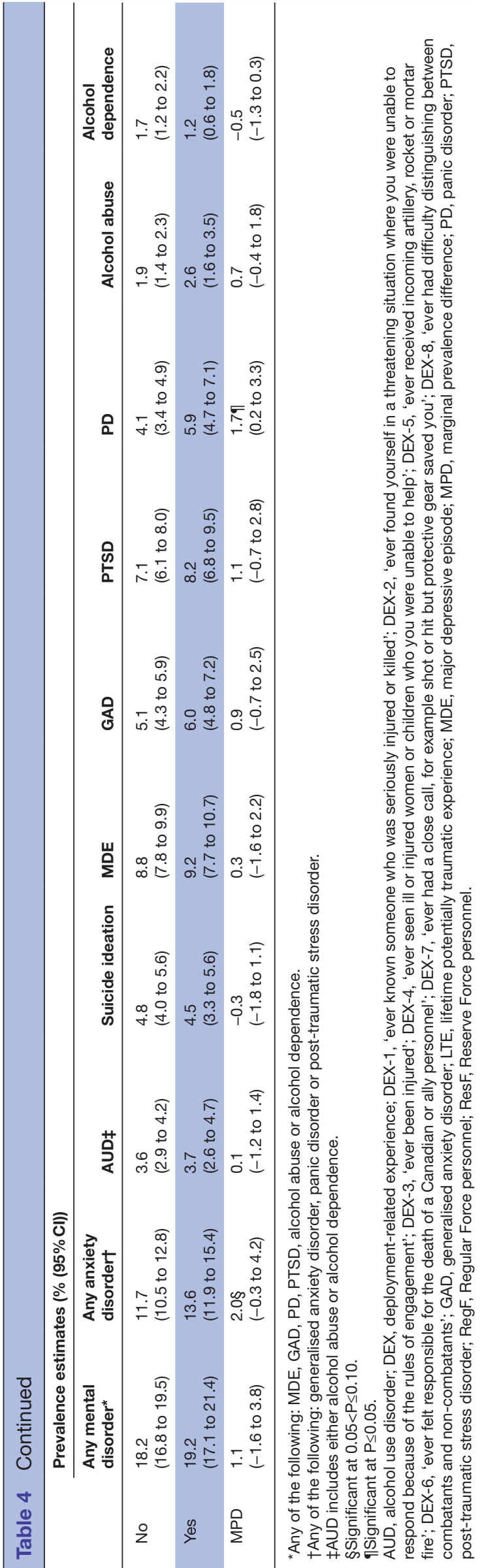

it was higher (39\% vs $31 \%$ ). Additionally, ResF reported more past-year civilian MHSU and not being eligible for CAF health services was the predominant specified reason.

\section{Comparison with other findings}

Others have identified MHP differences between their military's corresponding RegF and ResF personnel. A systematic review investigating mental disorders among US National Guard and Reserve service members relative to their active duty counterparts found much variability in individual estimates. ${ }^{29}$ While this review included both deployed and non-deployed personnel, it indicated that AUDs among the National Guard and Reserve service members were higher $(14.5 \%$ vs $11.7 \%)$ but depression and PTSD were not. Another US study noted that Reservists with a deployment in the past 36 months had similar or higher rates of MHP compared with active duty service members. ${ }^{17}$ These authors reported that among Reservists, the need for further depression evaluation $(19.1 \%$ vs $24.0 \%)$ and 30-day GAD symptomology (10.4\% vs $13.7 \%)$ were lower while 30-day PTSD symptomology $(8.4 \%$ vs $7.6 \%)$ and past-year suicide ideation $(7.1 \%$ vs $5.4 \%)$ were higher. A UK study investigating individuals with a deployment to Iraq identified Reservists to be more likely to have common MHP (26.3\% vs $19.4 \%)$ and PTSD (6.0\% vs $4.0 \%)$ outcomes but after adjustments for sociodemographic and potentially traumatising experiences, only PTSD remained significant. ${ }^{27}$ These authors further observed that PTSD also reached non-significance after adjusting for measures of unit cohesion and in-theatre duties.

Generally, the authors of these studies have argued that the observed postdeployment mental health differences between components were largely a result of differences in prior deployment experiences, preparation for and the process of deployment, as well as differential support for members and their families. ${ }^{1727}$ This contrasts with our own findings where the observed effect sizes changed some after adjusting for predeployment and postdeployment mental health training, LTE and DEX variables but ResF personnel remained less likely to have a pastyear anxiety disorder and more likely to have a past-year alcohol abuse disorder. It is possible that unmeasured experiences or perhaps specific training differences other than mental health training resulted in these observed MHP differences between components in the CAF.

Additionally, we observed lower MHSU among Reservists with MHP relative to RegF and this contrasts with no difference found by researchers in the UK. ${ }^{43}$ However, MHSU among military personnel has been observed to generally be lower when alcohol use problems are the sole disorder ${ }^{43-45}$ and this has been attributed to personnel not recognising that they suffer from a disorder. ${ }^{43}{ }^{44}$ In our study population, a higher fraction of ResF had only an AUD and this may partially explain some of their lower MHSU. However, barriers to accessing CAF mental healthcare may also play a role, especially as a higher fraction of ResF personnel indicated that they both needed help for 
Table 5 Past-year mental health services use and perceived helpfulness of the services among Regular Force and Reserve Force personnel with a mental disorder*

\section{Regular Force personnel \\ Sample $\mathrm{n}=603$ \\ Weighted $\mathrm{N}=5320$}

\section{Characteristic}

Past-year MHSU help venues consulted

$\begin{array}{lr}\text { 1) Psychiatrist } \dagger & 31.2 \\ \text { 2) Family doctor† } & 39.5 \\ \text { 3) Psychologist } \dagger & 38.0 \\ \text { 4) Nurse } \dagger & 24.9 \\ \text { 5) Social worker† } & 39.6 \\ \text { 6) OSISS } & 9.4 \\ \text { 7) Religious/spiritual advisor } & 13.2 \\ \text { 8) Family member† } & 47.0 \\ \text { 9) Friend } & 38.1 \\ \text { 10) Coworker/boss } \ddagger & 30.1 \\ \text { 11) Other† } & 1.5 \\ \text { No MHSU† } & 21.4 \\ \text { Hospitalised for MHP } & 3.0\end{array}$

Needed help for MHP but did not receive it $† 31.2$

Perceived level of help received from each help venue

\section{1) Psychiatrist}

Helped a lot

Helped some

Helped little or none

2) Family doctor

Helped a lot

Helped some

Helped little or none

3) Psychologist $†$

Helped a lot

Helped some

Helped little or none

4) Nurse

Helped a lot

Helped some

Helped little or none

5) Social worker

Helped a lot

Helped some

Helped little or none

46.2

26.9

26.9

6) Peer support coordinator-OSISS

Helped a lot

Helped some

36.0

28.0

Helped little or none

36.0
27.7 to 34.7

35.8 to 43.1

34.3 to 41.6

. 28.2

7.1 to 11.7

0.6 to 15.8

0.6 to 2.4

18.4 to 24.5

.8 to 4.2

6.1 to 49.3

4.5 to 46.3

2.5 to 33.2

8.9 to 50.9

8 to 38.5

21.6 to 32.2

21.6 to 32.3

23.5 to 48.5

15.5 to 40.5

23.2 to 48.8

\section{Reserve Force personnel \\ Sample $n=265$ \\ Weighted $\mathrm{N}=840$ \\ $\%$}

21.4

17.6 to 25.2

26.8

26.2

14.6

26.2

9.8

11.9

39.0

39.0

26.2

2.4

33.3

2.4

39.0

22.8 to 30.8

22.2 to 30.2

11.3 to 18.0

22.1 to 30.2

7.0 to 12.5

8.9 to 14.9

34.6 to 43.4

34.6 to 43.4

22.2 to 30.1

0.9 to 4.0

29.0 to 37.6

0.9 to 4.0

34.6 to 43.5

7) Religious/spiritual advisor 
Table 5 Continued

\begin{tabular}{|c|c|c|c|c|}
\hline \multirow[b]{3}{*}{ Characteristic } & \multicolumn{2}{|c|}{ Regular Force personnel } & \multicolumn{2}{|c|}{ Reserve Force personnel } \\
\hline & \multicolumn{2}{|c|}{$\begin{array}{l}\text { Sample } n=603 \\
\text { Weighted } N=5320\end{array}$} & \multicolumn{2}{|c|}{$\begin{array}{l}\text { Sample } n=265 \\
\text { Weighted } N=840\end{array}$} \\
\hline & $\%$ & $95 \% \mathrm{Cl}$ & $\%$ & $95 \% \mathrm{Cl}$ \\
\hline Helped a lot & 37.1 & 26.8 to 47.5 & 60.0 & 47.2 to 72.8 \\
\hline Helped some & 34.3 & 24.3 to 44.3 & 20.0 & 9.2 to 30.8 \\
\hline Helped little or none & 28.6 & 18.4 to 38.7 & 20.0 & 9.4 to 30.6 \\
\hline \multicolumn{5}{|l|}{ 8) Family member† } \\
\hline Helped a lot & 58.1 & 52.6 to 63.5 & 47.1 & 39.9 to 54.2 \\
\hline Helped some & 24.2 & 19.5 to 28.9 & 35.3 & 28.5 to 42.1 \\
\hline Helped little or none & 17.7 & 13.5 to 22.0 & 17.6 & 12.3 to 23.0 \\
\hline \multicolumn{5}{|l|}{ 9) Friend } \\
\hline Helped a lot & 38.6 & 32.6 to 44.6 & 37.5 & 30.2 to 44.8 \\
\hline Helped some & 35.6 & 29.7 to 41.5 & 43.8 & 36.4 to 51.1 \\
\hline Helped little or none & 25.7 & 20.3 to 31.1 & 18.8 & 13.1 to 24.4 \\
\hline \multicolumn{5}{|l|}{ 10) Coworker/boss } \\
\hline Helped a lot & 30.4 & 24.0 to 36.7 & 20.0 & 12.3 to 27.7 \\
\hline Helped some & 27.8 & 21.7 to 34.0 & 40.0 & 30.9 to 49.1 \\
\hline Helped little or none & 41.8 & 34.9 to 48.6 & 40.0 & 30.9 to 49.1 \\
\hline \multicolumn{5}{|l|}{ Other past-year MHSU } \\
\hline Past-year medication use $\dagger$ & 49.1 & 45.3 to 52.8 & 33.3 & 29.0 to 37.6 \\
\hline Past-year civilian MHSU† & 12.0 & 9.6 to 14.5 & 17.1 & 13.7 to 20.4 \\
\hline \multicolumn{5}{|l|}{ Reason for past-year civilian MHSU } \\
\hline 1) Not eligible for CAF health services & 0 & - & 28.6 & 18.2 to 38.9 \\
\hline 2) Waiting time too long for CAF care & 19.4 & 10.6 to 28.1 & 14.3 & 6.9 to 21.6 \\
\hline 3) Felt CAF care would be inadequate & 19.4 & 10.6 to 28.1 & 14.3 & 6.8 to 21.7 \\
\hline 4) Transportation problems & 0 & - & 0 & - \\
\hline 5) Language problems & 0 & - & 0 & - \\
\hline 6) Personal or family responsibilities & 6.5 & 0.9 to 12.0 & 0 & - \\
\hline 7) Concerned about confidentiality & 18.8 & 10.4 to 27.1 & 14.3 & 5.1 to 23.5 \\
\hline 8) Concerned about career & 18.8 & 10.1 to 27.4 & 16.7 & 7.3 to 26.1 \\
\hline 9) Did not want to take time offł & 6.5 & 0.9 to 12.0 & 14.3 & 5.8 to 22.8 \\
\hline 10) Other & 45.2 & 34.2 to 56.1 & 42.9 & 32.1 to 53.6 \\
\hline
\end{tabular}

*Any of the following: major depressive episode, generalised anxiety disorder, panic disorder, post-traumatic stress disorder, alcohol abuse disorder or alcohol dependence disorder. The survey assessed for these past-year disorders using the WHO's Composite International Diagnostic Interview, version 3.0.

†Regular Force and Reserve Force differ significantly (Wald $\left.\mathrm{X}^{2} \mathrm{P} \leq 0.05\right)$.

$\ddagger$ Regular Force and Reserve Force differ with marginal significance (Wald $X^{2} 0.05<P \leq 0.10$ ).

CAF, Canadian Armed Forces; MHP, mental health problem; MHSU, mental health services use; OSISS, Operational Stress Injury Social Support.

MHP but did not receive it and had more past-year civilian MHSU, with not being eligible for CAF health services reported as one of the primary reasons for its non-use. We also note here that the frequently chosen 'other' category for why services were not accessed among ResF members suggests that the Canadian Forces Mental Health Survey may not have measured some of the leading obstacles to care for this population, something that future research should pursue.

\section{Limitations}

Our study's primary limitation relates to its use of a cross-sectional design and the associated limitations (eg, recall bias, information bias, unknown temporal sequence, and so on). For example, a precise date for onset of the measured disorders and the various deployment experiences relative to individuals' Afghanistan-related deployment return prevented more detailed assessments that could take temporality into account. The 
study only included individuals who were serving when the study was implemented and personnel with mental disorders have a significantly elevated risk of release from military service. ${ }^{46}$ Hence, the failure to include the more than 10000 personnel with an Afghanistan-related deployment who had left service prior to the survey ${ }^{31}$ means that the present findings presumably represent a systematic underestimate of MHP and reported MHSU among all CAF personnel who had an Afghanistan-related deployment. Additionally, social support and social environment were only cursorily controlled for (eg, marital status and financial difficulties as proxies) with our analyses and these factors may have played a role in the development of MHP. Moreover, this study used the CIDI to assess mental disorder outcomes and these were based on DSM IV criteria. This would be a limitation for generalising the results to a DSM V environment. In DSM V, alcohol abuse and alcohol dependence have been merged into a single AUD and PTSD is no longer considered an anxiety disorder; the criteria for these disorders also differ slightly relative to DSM IV.

\section{Implications}

Among serving personnel who deployed on the CAF mission in Afghanistan, we found some modest but significant MHP differences between ResF and RegF and these contrast with observations from Canada's allies. ${ }^{17} 27$ The higher prevalence of AUDs observed among ResF and the high association of MHP with DEX-6, a DEX associated with moral injury, suggest that it might be beneficial to augment CAF mental health training to further include the concept of moral injury and to enhance awareness of AUDs, especially for ResF training.

While some authors identify a number of facilitators to mental health care-seeking, features that may directly have a positive influence on barriers to care-seeking, such as the presence of a supportive organisational climate, social support and mental health education, and public awareness programmes that promote treatment-seeking, ${ }^{47}$ it has been found that a positive pathway to MHSU often begins with the self-recognition of an MHP requiring help. ${ }^{49}$ ResF personnel's lower MHSU when an MHP was present, particularly CAF services, suggests that there may be a lack of recognition of a problem and/or barriers to accessing care. Further work in this area is needed to delineate the issues at play and to investigate whether RegF and ResF personnel differ in their perception of CAF mental health services and their perceived barriers to such care. While our findings are focused within the Canadian military, they provide a point of comparison for other military that have similar mental health systems.

\section{CONCLUSION}

Past-year MHP differences between currently serving $\mathrm{RegF}$ and ResF personnel were identified and these largely persisted after adjustment for potential confounders. The findings suggest that although DEXs were highly associated with MHP, these experiences only partially accounted for MHP differences between CAF components with an Afghanistan-related deployment. Additional research is needed to further investigate the MHSU differences we identified between components.

Acknowledgements We thank Mark Zamorski for his initial thoughts on the study and its analysis.

Contributors Both authors contributed to the study. DB conducted all the analyses and wrote the initial draft of the manuscript. Both DB and DF contributed to the interpretation of the study results as well as the writing and revising of the final manuscript. Both DB and DF have read and agree with the manuscript's final content.

Funding This work was supported by funding from the Canadian Armed Forces Surgeon General's Medical Research Program.

Competing interests Both DB and DF report that they are employees of the Canadian Department of National Defence and funding for this research came via this federal government department.

Patient consent Obtained.

Ethics approval All aspects of the data collection, access and analysis underwent ethical and privacy review by the relevant entities at Statistics Canada.

Provenance and peer review Not commissioned; externally peer reviewed.

Data sharing statement The data used in this study came from the Canadian Armed Forces 2013 Mental Health Survey. The data were collected and are maintained by Statistics Canada. These data are available through Statistics Canada for additional analyses provided that their procedures for authorised access are followed.

Open Access This is an Open Access article distributed in accordance with the Creative Commons Attribution Non Commercial (CC BY-NC 3.0) license, which permits others to distribute, remix, adapt, build upon this work non-commercially, and license their derivative works on different terms, provided the original work is properly cited and the use is non-commercial. See: http://creativecommons.org/ licenses/by-nc/3.0/

(c) Article author(s) (or their employer(s) unless otherwise stated in the text of the article) 2018. All rights reserved. No commercial use is permitted unless otherwise expressly granted.

\section{REFERENCES}

1. Hoge CW, Castro CA, Messer SC, et al. Combat duty in Iraq and Afghanistan, mental health problems, and barriers to care. $N$ Engl J Med 2004;351:13-22.

2. Hoge CW, Auchterlonie JL, Milliken CS. Mental health problems, use of mental health services, and attrition from military service after returning from deployment to Iraq or Afghanistan. JAMA 2006;295:1023-32.

3. Wells TS, LeardMann CA, Fortuna SO, et al. A prospective study of depression following combat deployment in support of the wars in Iraq and Afghanistan. Am J Public Health 2010;100:90-9.

4. Smith TC, Ryan MA, Wingard DL, et al. New onset and persistent symptoms of post-traumatic stress disorder self reported after deployment and combat exposures: prospective population based US military cohort study. BMJ 2008;336:366-71.

5. Fear NT, Jones M, Murphy D, et al. What are the consequences of deployment to Iraq and Afghanistan on the mental health of the UK armed forces? A cohort study. Lancet 2010;375:1783-97.

6. Wells TS, Miller SC, Adler AB, et al. Mental health impact of the Iraq and Afghanistan conflicts: a review of US research, service provision, and programmatic responses. Int Rev Psychiatry 2011;23:144-52.

7. Cohen BE, Gima K, Bertenthal D, et al. Mental health diagnoses and utilization of VA non-mental health medical services among returning Iraq and Afghanistan veterans. J Gen Intern Med 2010;25:18-24.

8. Rost K, Smith JL, Dickinson M. The effect of improving primary care depression management on employee absenteeism and productivity. A randomized trial. Med Care 2004;42:1202-10.

9. Wang JL. Perceived work stress, imbalance between work and family/personal lives, and mental disorders. Soc Psychiatry Psychiatr Epidemiol 2006;41:541-8. 
10. Armed Forces Health Surveillance Center. Hospitalizations among members of the active component, U.S. Armed Forces, 2009. MSMR 2010;17:3-9.

11. Armed Forces Health Surveillance Center. Ambulatory visits among members of the active component, U.S. Armed Forces, 2009. MSMR 2010;17:10-15.

12. Armed Forces Health Surveillance Center. Absolute and relative morbidity burdens attributable to various illnesses and injuries, U.S. Armed Forces, 2009. MSMR 2010;17:16-21.

13. Boulos D, Zamorski MA. Deployment-related mental disorders among Canadian Forces personnel deployed in support of the mission in Afghanistan, 2001-2008. CMAJ 2013;185:E545-52.

14. Riddle JR, Smith TC, Smith B, et al. Millennium Cohort: the 20012003 baseline prevalence of mental disorders in the U.S. military. $J$ Clin Epidemiol 2007:60:192-201.

15. Bean-Mayberry B, Yano EM, Washington DL, et al. Systematic review of women veterans' health: update on successes and gaps. Womens Health Issues 2011;21(4 Suppl):S84-S97.

16. Griffith J. Decades of transition for the US reserves: changing demands on reserve identity and mental well-being. Int Rev Psychiatry 2011;23:181-91.

17. Lane ME, Hourani LL, Bray RM, et al. Prevalence of perceived stress and mental health indicators among reserve-component and active-duty military personnel. Am J Public Health 2012;102:1213-20.

18. Sareen J, Henriksen CA, Bolton SL, et al. Adverse childhood experiences in relation to mood and anxiety disorders in a population-based sample of active military personnel. Psychol Med 2013;43:73-84.

19. Reger MA, Gahm GA, Swanson RD, et al. Association between number of deployments to Iraq and mental health screening outcomes in US Army soldiers. J Clin Psychiatry 2009;70:1266-72.

20. Buckman JE, Sundin J, Greene T, et al. The impact of deployment length on the health and well-being of military personnel: a systematic review of the literature. Occup Environ Med 2011;68:69-76.

21. Donoho CJ, Bonanno GA, Porter B, et al. A Decade of War: Prospective Trajectories of Posttraumatic Stress Disorder Symptoms Among Deployed US Military Personnel and the Influence of Combat Exposure. Am J Epidemiol 2017;186:1310-8.

22. Moore TM, Risbrough VB, Baker DG, et al. Effects of military service and deployment on clinical symptomatology: The role of trauma exposure and social support. J Psychiatr Res 2017;95:121-8.

23. Bonanno GA, Mancini AD, Horton JL, et al. Trajectories of trauma symptoms and resilience in deployed U.S. military service members: prospective cohort study. Br J Psychiatry 2012;200:317-23.

24. Nash WP, Marino Carper TL, Mills MA, et al. Psychometric evaluation of the Moral Injury Events Scale. Mil Med 2013;178:646-52.

25. Wilk JE, Bliese PD, Kim PY, et al. Relationship of combat experiences to alcohol misuse among U.S. soldiers returning from the Iraq war. Drug Alcohol Depend 2010;108:115-21.

26. Killgore WD, Cotting DI, Thomas JL, et al. Post-combat invincibility: violent combat experiences are associated with increased risk-taking propensity following deployment. J Psychiatr Res 2008;42:1112-21.

27. Browne T, Hull L, Horn O, et al. Explanations for the increase in mental health problems in UK reserve forces who have served in Iraq. Br J Psychiatry 2007;190:484-9.

28. Russell DW, Cohen GH, Gifford R, et al. Mental health among a nationally representative sample of United States Military Reserve Component Personnel. Soc Psychiatry Psychiatr Epidemiol 2015:50:639-51.

29. Cohen GH, Fink DS, Sampson L, et al. Mental health among reserve component military service members and veterans. Epidemiol Rev 2015;37:7-22.
30. Lee JE, Phinney B, Watkins K, et al. Psychosocial pathways linking adverse childhood experiences to mental health in recently deployed canadian military service members. J Trauma Stress 2016;29:124-31.

31. Zamorski MA, Bennett RE, Boulos D, et al. The 2013 Canadian forces mental health survey: background and methods. Can J Psychiatry 2016;61(1 Suppl):10S-25.

32. Holton T, Peach J, Sullivan-Kwantes W, et al. Reintegration satisfaction among CF Reservists. TM 2013-023 ed. Toronto, Canada: Department of National Defence, 2013.

33. Haro JM, Arbabzadeh-Bouchez S, Brugha TS, et al. Concordance of the Composite International Diagnostic Interview Version 3.0 (CIDI 3.0) with standardized clinical assessments in the WHO World Mental Health surveys. Int J Methods Psychiatr Res 2006;15:167-80.

34. Kessler RC, Ustün TB. The World Mental Health (WMH) Survey Initiative Version of the World Health Organization (WHO) Composite International Diagnostic Interview (CIDI). Int J Methods Psychiatr Res 2004;13:93-121.

35. Boulos D, Zamorski MA. Contribution of the Mission in Afghanistan to the Burden of Past-Year Mental Disorders in Canadian Armed Forces Personnel, 2013. Can J Psychiatry 2016;61(1 Suppl):64S-76.

36. Walsh CA, MacMillan HL, Trocmé N, et al. Measurement of victimization in adolescence: development and validation of the Childhood Experiences of Violence Questionnaire. Child Abuse Negl 2008;32:1037-57.

37. Bailey S. The Canadian Forces Health Services Road to Mental Readiness Programme. Medical Corp International Forum 2015. Bonn, Germany: Beta Publishing Group, 2015:37-9.

38. Sudom K, Watkins $\mathrm{K}$, Born J, et al. Stressors experienced during deployment among Canadian Armed Forces personnel: Factor structure of two combat exposure scales. Military Psychology 2016;28:285-95.

39. Wolter KM. Introduction to variance estimation. New York (NY: Springer-Verlag, 1985.

40. Bennett R, Zamorski MA. Patterns of occupational and nonoccupational trauma exposure in Canadian military personnel. Poster session presented at the Annual Meeting of the International Society for Trumatic Stress Studies. New Orleans, LA, 2015.

41. VanderWeele TJ, Knol MJ. A Tutorial on Interaction. Epidemiol Method 2014:3:33-72.

42. Muller CJ, MacLehose RF. Estimating predicted probabilities from logistic regression: different methods correspond to different target populations. Int J Epidemiol 2014;43:962-70.

43. Iversen AC, van Staden L, Hughes $\mathrm{JH}$, et al. Help-seeking and receipt of treatment among UK service personnel. Br J Psychiatry 2010;197:149-55.

44. Hines LA, Goodwin L, Jones M, et al. Factors affecting help seeking for mental health problems after deployment to Iraq and Afghanistan. Psychiatr Serv 2014;65:98-105.

45. Fink DS, Sampson L, Tamburrino MB, et al. Lifetime and 12-month use of psychiatric services among U.S. Army National Guard soldiers in Ohio. Psychiatr Serv 2015;66:514-20.

46. Boulos D, Zamorski MA. Military Occupational Outcomes in Canadian Armed Forces Personnel with and without DeploymentRelated Mental Disorders. Can J Psychiatry 2016;61:348-57.

47. Zinzow HM, Britt TW, McFadden AC, et al. Connecting active duty and returning veterans to mental health treatment: interventions and treatment adaptations that may reduce barriers to care. Clin Psychol Rev 2012;32:741-53

48. Fikretoglu D, Guay S, Pedlar D, et al. Twelve month use of mental health services in a nationally representative, active military sample. Med Care 2008:46:217-23.

49. Murphy D, Hunt E, Luzon O, et al. Exploring positive pathways to care for members of the UK Armed Forces receiving treatment for PTSD: a qualitative study. Eur J Psychotraumatol 2014;5:21759. 